\title{
RETURN CURRENT INSTABILITY IN FLARES
}

\author{
D. Cromwell' P'. MaQuillan" J.C. Brown \\ Dept. of Physics and Astronomy', \\ University of Cilasgow, Cil2 8QW, U.K
}

\begin{abstract}
.
We consider the problem of ion-acoustic wave generation, and resultant anomalous Joule heating, by a return current driven unstable by a small-area thick-target electron beam in solar llares. We find hat, contrary to the usual assumplion, the hatd X-raly bremsstrahlung emission may actually be enhanced in comparison to conventional thicklarget models. This present paper is a summary of the work of Cromvell, MeQuillan and Brown (1088).
\end{abstract}

\section{Introduction.}

It is now commonly believed that electron beams propagating driwnwards in the solar atmosphere plicy a major role in the production, by collisional bremsistralilung, of hard $X$-ray bursts during the impulsive phase of solar flares. Electron beam injection sets up a cospiztial, beam-neutralising return current (c.g. Iloy'lng, lbrown and van 13eck, 1976). Therefore, the beam loses additional encrgy in driving the return current against the finite resistivity of the plasma. We might well ask: Does this aggravate the low efliciency problem of thick target models? What effect does return current instability have on hard X-ray production?

Electrostatic wave generation by an unstable return current will lead to anomalously large values of resistivity. (Here we consider the ion-acoustic instability ats this has the lowest threshold drift speed in an unmagnetized plasmal. The eflect on hard X-ray emission will be twofold:

(a) The electric field driving the return current will rise, reducing the lifetime of bean electrons. Therefore, the nonthermal yield will decrease.

(b) Plisma heating, $\| j^{2}$, will rise. Therefore, the thermal yield will increase.

1 Presenl address: NCAR, High Allicude Obscrualory, Boulder, Colorado, U.S.A.

2 Prescnt address: Scollish Life Assurance, E'dinburgh, U.K. 


\section{Model.}

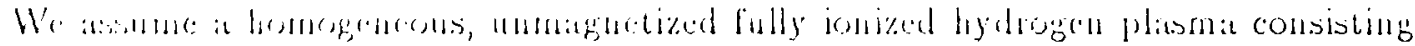

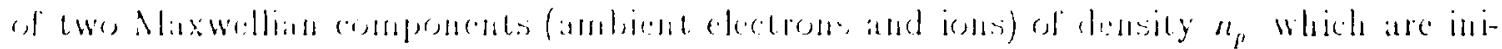

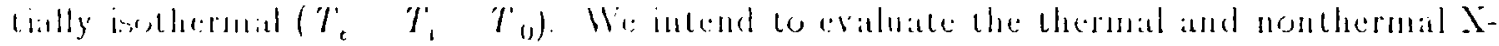

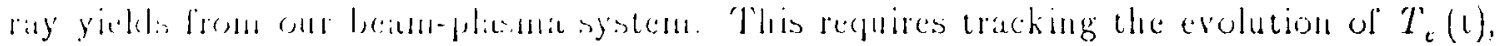

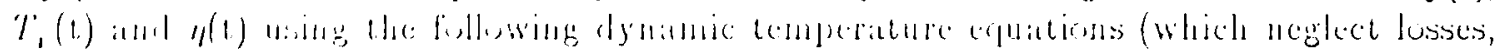
li, simplicity):

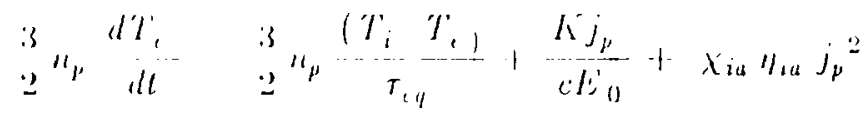

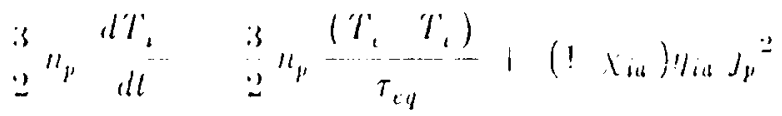

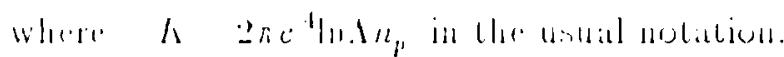

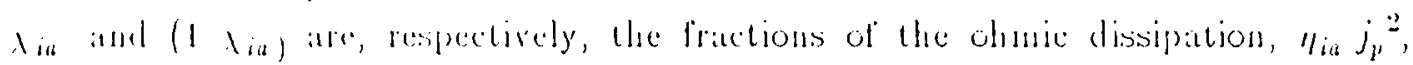

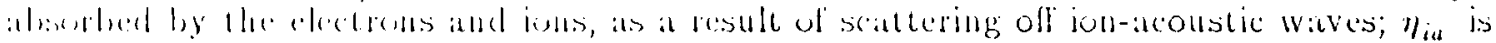

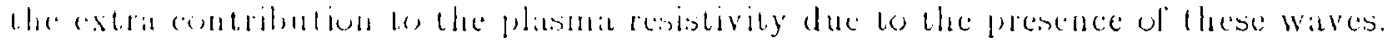

The larating, aluations (1) and (2) apply to the cylindrical volume bounded by the

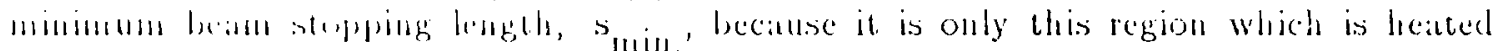
crintimundy throughoul the simulition. Due to Coulomb collisions and Ohmic dissipa-

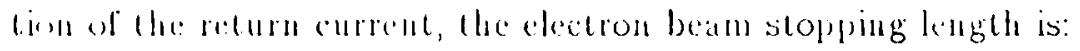

$$
\therefore \quad \frac{E_{0}}{c i_{p}\left(K / S_{0}\right)}
$$

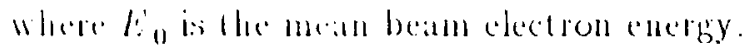

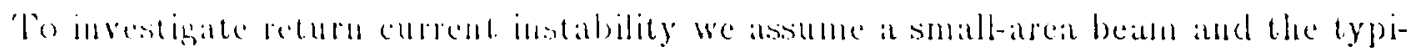

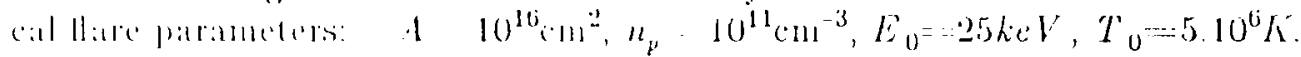

\section{Mlarginal Stability Approach.}

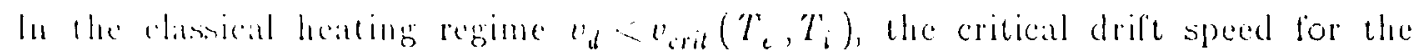
umal of iun-ikcustic instability, and $\|_{i a}-0$. Equations (1) and (2) can then be solved

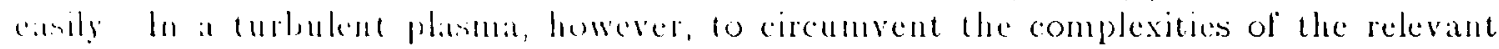

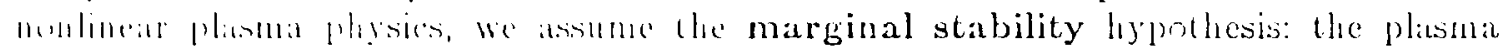
remains on the houndary belween unstable groweh and damping for that particulat

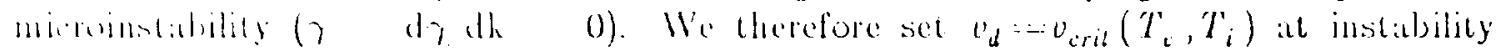
(111:-14.

Whe have a preseribed heam current evolution, $j_{b}(1)=-j_{p}(l)$, in our model: a lincarly increasins lunction of time, from zero to a typical latge electron flux of $10^{36} \mathrm{~s}^{-1}$ wer lhe heam rise lime. $l_{r}$ Therefore, since $b_{1}(l)=\frac{j_{p}(l)}{n_{p} e}$ is known, we can sölve

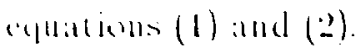


We wish to calculate the thermal bremsstrahlung from the rapielly heated plasmint For comparison, we evaluate the conventional thick-tatget nonthermal bremsstrahlung from the sante beam but with Coulomb collisional losses only (as would be relevant to at beam wilh latrger area $\left.1 \sim 10^{18} \cdot 10^{19} \mathrm{~cm}^{2}{ }^{2}\right)$.

Adopting reasonable beam and atmosplueric parameters we lime that rapid anomitous Olnuic healing occurs in a subst.untial plasmat volume. This latge hot plasma emits thermal bremsstralulung hard X-rays ( $200 \mathrm{hel}$ ) comparable to, or cxceeding, the nonthermal bremsstrahlung which would have been emitted in a conventional collisional chick target.

However, it turns out that there is a contraliction which cant arise in the marginal stability treatment in some parameter regimes. Its origin is most easily demonstrated by retaining only the anomalous (ion-acoustic) terms in equations (1) and (2). Applying the condition of marginal stability leads to:

$$
\eta_{i a}^{M S} \sim \frac{T_{c}^{1 / 2}}{1-x_{i a}^{M S S}\left(1+\frac{T_{i}}{2 T_{c}}\right)}
$$

where:

$$
X_{i a}^{M S}=: 1-\frac{c_{8}}{v_{\text {cril }}}
$$

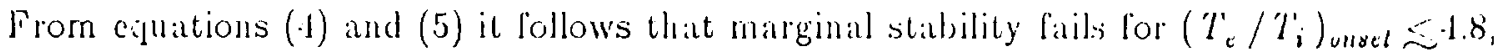
since negative, i.e. unpluysical, values of resistivity are oblatined. Or, equivalently, for our prescribed beam curent cvolution, failure occurs for sufficienlly ripid beim rise times, $t_{r} \leqslant 1 \mathrm{~s}$. For $T_{\epsilon} / T_{i} \lesssim 4.8$ a marginally stable plasma evolution is not possible: the dual constraints of a driving electron beam and the heating properties of ion-acoustic waves are incompatible in marginal stability.

The lailure of marginal stability in this regime is, we belicve, directly related to the neglect of platsma wave cuergy deusity, $W$, in the energy equations (1) and (2). Underlying the marginal stability hypothesis is the assumption that alV/ $l l \cdots=0$ only over negligribly short times compared to the heating tinescale. Il this is not true then $\mathrm{W}^{\prime}$ will become much larger and then the plasina would be even more rapilly heated, on times-

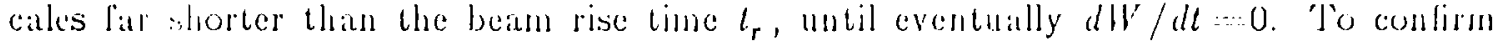
this interpetation we have conducted numerical sinulations (Cromwell, 1087) on feamdriven ion-acoustic wave growth. These simulations thow that, for $T_{t} / T_{i}=-1.8$, the wates are rapidly switched on and ofl, ats the plasma scillates about the manginal atability curre, and that the values of $W^{\prime}$ and $d W^{\prime} / d$ remain very isw; matreilual stability is, cherefore, applicable here. However, for $T_{t} / ?_{i}<48$, non-negligible values of $W^{\prime}$ and dl' $/ \mathrm{dt}$ are indeed attained and very rapid heating occurs. In hlese cases, the marginal stability concept is no longer applicable becatuse the form of the driver is incompatible: with zero walve growth rate at these $l_{c}^{\prime} / T_{i}$ alld must be replaced by an allessative method (i.e., a proper wave growth andysis). 


\section{Conclusions}

Our work may be summarized ats follows. For $\left(T_{t} / T_{i}\right)_{\text {onst }} \gtrsim \mathbf{1} 8$ (i.e beall rixt lime $\left.t_{r}=1: s\right)$, Ohmic dissipation of a beam-driven return current can result in a higher hatd X-ray bremsistrahlung efficiency than in a conventional collisional thick tatget. For

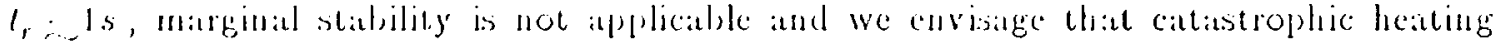
will occur in small volumes. Once lhe value of $T_{t} / T_{i}$ hats increased sufliciently in such

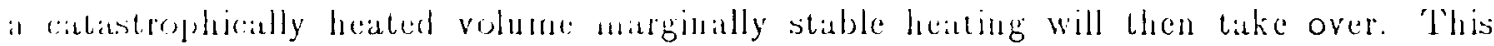

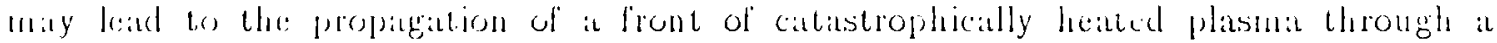

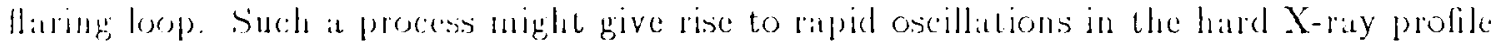
(rle Kiplinger al al., 19833).

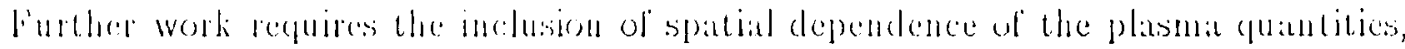

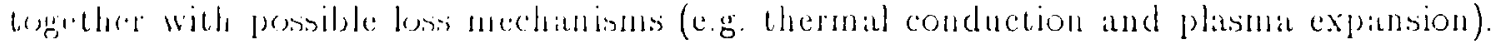

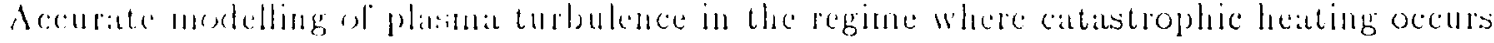
i:i al:ore cortianly deciralsk:

In conclusion, we helieve that the essedntial result presented here of enhanded Ohmic

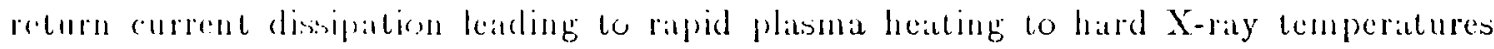
will remain unaltered. The simple model we have deseribed hats yielded useful informatlion and dearly demonstrated lhe importance of return current instability on the lated X-raty signature ol flares.

\section{Acknowledgements}

We gratelully acknowledge the linancial support of a SLEC Resuarch Grant and siudentship, and vatuable discossions with Prof. P.A. Sivect, Prof J.W. Laing, and Dr. A.1. Nathinnon in the contse of our research. This paper was prepared at NCAlR (which is sponsored hy the Nitional science lioundation) with technical assistance from Ms. limbia Crom

\section{References}

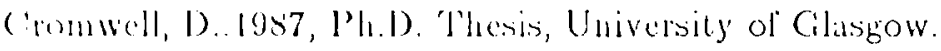

('romwell, D)., M.Quillan, P'., and Brown, J.C.: 1088, Solar Phys. 115, 289.

Ilogng, I'., Brown, J.C., anil vaii Beok, 11.1'. 1976, Solur Phys. 48, 197.

Kiplinger, A.L., Dennis, B.R., Emslie, A.G., Frost, K.J., and Orwig, L.L.:1983, Ap.J. (litleris), $265,1.99$. 